\title{
A Great Opportunity to Meet and Learn from Peripheral Nerve Experts
}

\author{
David Chwei-Chin Chuang, MD*; Fu-Chan Wei, MD, FACS; Tommy Nai-Jen Chang, MD; Johnny Chuieng-Yi Lu, MD; \\ Evelyn Ting-Hsuan Tang, MS \\ Division of Reconstructive Microsurgery, Department of Plastic and Reconstructive Surgery, Chang-Gung Memorial Hospital; Chang-Gung \\ University, College of Medicine, Taoyuan, Taiwan
}

$\mathrm{M}$ any microsurgeons involved in reconstructive microsurgery would like to better understand brachial plexus injury, a condition for which patient evaluation, diagnosis, operative planning, and surgical treatment can be quite challenging.

In 2009, we hosted a highly successful, two-day instructional course on the topic of adult brachial plexus injuries (BPIs) at the Linkou-Chang Gung Memorial Hospital. In addition to lectures and a unique two-hour Q\&A panel, this course also featured live surgeries, including three nerve reconstructions on the first day and three functioning free muscle transplantations on the second day. Over 50 domestic surgeons and 100 international surgeons from 24 countries attended, all of whom provided positive feedback and requested that a 2 nd course be held in the future.

Seven years have passed since the first instructional course, and techniques and strategies used to treat BPI have continued to evolve. Indeed, since the first course, two more surgeons (Dr. Tommy Chang and Dr. Johnny Lu) have joined our team, and we have treated over 2000 adults with BPI by way of brachial plexus exploration and reconstruction. We believe that now is the right time for a second instructional course on adult BPIs, and have set the course dates to run from November 13-16, 2017. The 2nd instructional course will be four days long. The first day will feature a reception. Days 2 and 3 will begin with the examination of a preoperative patient by multiple surgeons. This will be followed by EMG interpretation, a lecture by our neurologist, MRI imaging analysis, and a lecture by our radiologist. Finally, course participants will be invited to observe four live surgeries. To be more specific, day 2 will focus on nerve reconstruction on four different patients suffering from total root avulsion or incomplete root avulsion, level II or III and level IV. Day 3 will focus on functioning free muscle transplantation and other types of palliative reconstruction (i.e. tendon transfers or arthrodesis). Live surgeries will be performed between 8:30 AM and 3:00 PM, to be followed by lectures from invited faculty in the afternoon. Day 4 will feature special lectures and will end with a special interactive $Q$ \& A panel at noon.

\footnotetext{
*Correspondence: David Chwei-Chin Chuang, MD

Division of Reconstructive Microsurgery, Department of Plastic and Reconstructive Surgery, Chang-Gung Memorial Hospital; Chang-Gung University, College of Medicine, Taoyuan, Taiwan.

E-mail: dearchuang@gmail.com
}

Received: June 16, 2017; Accepted: June 17, 2017; Published: Oct. 12, 2017

International Microsurgery Journal. 2017;1(2):4

DOI: $10.24983 /$ scitemed.imj.2017.00019

Copyright $\odot 2017$ The Author(s). This is an open-access article distributed under the terms of the Creative Commons Attribution 4.0 International License (CC-BY).
Distinguished experts in the field of BPI treatment will be in attendance, including Dr. A Gilbert (France; moderator and lecturer), Dr. Christophe Oberlin (France; operator, moderator and lecturer), Dr. Zoubir Belkheyar (France; operator, moderator, and lecturer), Dr. Shu-Feng Wang (China, moderator and lecturer), Dr. Yasunori Hattorri (Japan; operator and lecturer), Dr. Somsak Leechanvengvongs (Thailand; operator, moderator and lecturer), Dr. Tessa Gordon (Canada; moderator and lecturer), Dr. Anil Bhatia (India; operator, moderator and lecturer), and Dr. Yuan-Kun Tu (Taiwan; operator and lecturer).

Expert medical staff from Chang-Gung hospital involved in this course include Dr. Kee-Min Yeow (radiologist, moderator, and lecturer), Dr. Kuo-Hsuan Chang (neurologist, moderator, and lecturer), and Ms. Shu-Jung Ju (therapist and lecturer), as well as surgical team members Dr. Tommy Nai-Jen Chang, Dr. Johnny Cheiung-Yi Lu, and Dr. David Chwei-Chin Chuang (surgeon, moderator, and lecturer).

The 2 nd instructional course for adult brachial plexus injuries is a fantastic opportunity to meet and learn from experts in the field. We cordially invite you to visit Chang Gung Memorial Hospital to participate in this unique learning experience.

We would also kindly ask that you help spread the word about the opportunity to attend this unique instructional course to your colleagues. We look forward to seeing you.

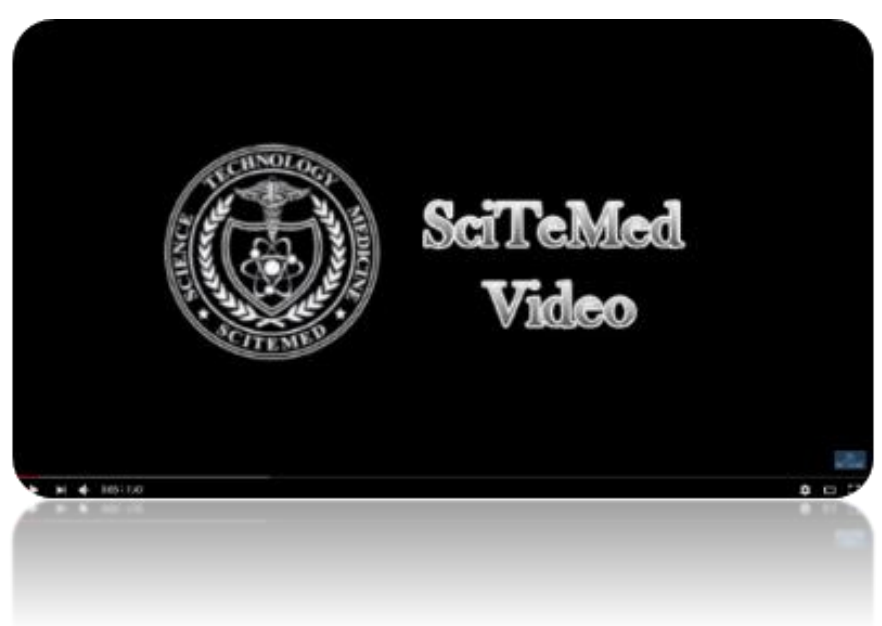

